\title{
Hepatocyte Growth Factor Is a Reliable Marker for Efficient Anti-Bacterial Therapy within the First Day of Treatment
}

\author{
Hossin Abednazari1, Lars Brudin'2,3, Gabriel Almroth4, Ingela Nilsson5, Fariba Nayeri1* \\ ${ }^{1}$ Division of Infectious Diseases, Department of Medical and Health Sciences, University Hospital, Linköping and \\ PEAS Institute, Linköping, Sweden \\ ${ }^{2}$ Department of Clinical Physiology, University Hospital, Linköping, Sweden \\ ${ }^{3}$ Department of Medical and Health Sciences, University Hospital, Linköping, Sweden \\ ${ }^{4}$ Department of Nephrology, University Hospital, Linköping, Sweden \\ ${ }^{5}$ Department of Clinical Chemistry, Kalmar County Hospital, Kalmar, Sweden \\ Email: ${ }^{*}$ fariba.nayeri@lio.se, ${ }^{*}$ farna@imk.liu.se
}

Received 3 July 2014; revised 17 August 2014; accepted 11 September 2014

Copyright (C) 2014 by authors and Scientific Research Publishing Inc.

This work is licensed under the Creative Commons Attribution International License (CC BY).

http://creativecommons.org/licenses/by/4.0/

(c) (;) Open Access

\section{Abstract}

Rapid diagnosis and choice of appropriate antibiotic treatment might be life-saving in serious infectious diseases. Still the available markers that can evaluate and monitor the diagnosis and treatment are few. Hepatocyte growth factor (HGF) has been studied as a potent regenerative factor produced and released during injuries such as infectious diseases. Monitoring of HGF levels might predict therapy results better than C-reactive protein (CRP) within the first day of treatment in pneumonia. For further investigation of previous observations we aimed to study HGF as a first-day marker in over-representing infectious diseases in comparison to procalcitonin (PCT), CRP and body temperature. Fifty-one patients with community acquired infectious diseases were included consequently at admittance and the serum samples were collected before and within 18 24 hours of treatment. HGF levels decreased significantly in case of efficient antibiotic therapy and HGF was shown to be better than PCT, CRP and body temperature to evaluate treatment. In patients with pneumonia, monitoring of HGF was most reasonable. HGF might be used as a therapeutic marker within the first day of empiric antibiotic treatment during infection.

\section{Keywords}

Hepatocyte Growth Factor, C-Reactive Protein, Procalcitonin, Temperature, Antibacterial Therapy

*Corresponding author.

How to cite this paper: Abednazari, H., et al. (2014) Hepatocyte Growth Factor Is a Reliable Marker for Efficient Anti-Bacterial Therapy within the First Day of Treatment. Advances in Bioscience and Biotechnology, 5, 823-830.

http://dx.doi.org/10.4236/abb.2014.510096 


\section{Introduction}

Patients with bacterial infections are at high risk of developing serious complications, such as septic shock and multiple organ failure, if treatment is not initiated in a timely manner. Therefore, empiric antibiotic treatment is initiated as soon as infection is suspected and cultures and/or other diagnostic tests are procured. However, it can take several days before culture results are available and an appropriate antibiotic regime is chosen. During that time, the physician must decide to continue or change the initial choice of antibiotic. The patient's clinical signs, such as respiratory and circulatory status, are still the most reliable markers for judging the efficacy of treatment. However, most physicians choose to examine additional markers at early stages, particularly in high-risk patients admitted to intensive care units so that therapy may be closely evaluated [1]. Monitoring body temperature [2], C-reactive protein (CRP) [3] [4], procalcitonin (PCT) [5] and interleukin 6 (IL-6) [6] are some of the more commonly used markers.

Hepatocyte growth factor (HGF) concentration increases during organ damage such as that caused by infectious diseases [7] [8]. HGF has potent regenerative properties [9] and the addition of exogenous HGF may inhibit and/or treat chronic organ injuries [10] [11]. We previously examined HGF levels in pneumonia and showed that the presence of HGF correlated significantly with survival in this patient group [12]. We also showed that HGF concentration increased in serum and exhaled-breath condensate in patients with pneumonia [13] and that the amount of HGF decreased markedly within 48 hours of initiation of the appropriate antibiotic therapy [14]. In another study, we showed that HGF predicted the results of antibiotic therapy better than CRP did within 24 hours of initiation of pneumonia treatment [15]. In the present study, we compared the ability of HGF (compared with body temperature, CRP and PCT) to predict the efficacy of antibiotic treatment within 24 hours of treatment initiation in 51 patients with varying infectious diseases.

The study aims to identify a means of judging the efficacy of empiric therapy early in the treatment of serious bacterial infections so that correct treatment may be pursued in a timely manner.

\section{Patients and Methods}

\subsection{Study Participants}

Those patients who came to the emergency unit of the University Hospital in Linköping between 11:00 - 19:00 on weekdays between October 2003 and March 2005 and were admitted to the Department of Infectious Diseases (inclusion criteria) were asked by the project nurse to join the study. There were no exclusion criteria. Written consent was obtained from the participants. The ethics committee in Linköping, Sweden, approved the study protocol (01-396). Ninety-five patients agreed to join the study and we obtained the first blood samples. The patients received empiric antibiotic therapy. However, 31 patients did not complete the study because they returned to their homes or were sent to other clinics before the second blood tests, within 24 hours of admission, could be collected. Blood samples were drawn from the remaining 64 patients (age range, 20 - 99 years; mean age, 69 years; median age, 74 years; males, 35) before and within 18 - 24 hours of antibiotic treatment initiation. The samples were then sent to project staff members for testing while the physician in charge performed diagnostic procedures and oversaw treatment. Within 30 minutes of drawing, the blood samples were centrifuged at $3000 \mathrm{~g}$ for ten minutes; plasma was separated and kept frozen after separation at $-70^{\circ} \mathrm{C}$. The patients were then discharged or moved to other clinics within a few days of admission, based on their clinical outcome. The samples were simultaneously analyzed to determine HGF, CRP and PCT concentrations. The project leader examined the medical records and the medical history of each patient, and patient research files were updated daily to include the results of routine laboratory tests, x-rays, endoscopic procedures, and the final diagnosis before patient discharge. Patients were tracked for one year after inclusion in this study to determine the ultimate diagnosis and outcome.

Thirty-one patients had infections of the respiratory system (Table 1), with symptoms such as fever, cough and typical X-ray changes. Ten patients had urinary tract infections (Table 2) and another ten patients had skin and soft tissue infections (Table 3). The remaining patients $(n=13)$ had cancerous tumours $(n=3)$, fevers of unknown origin $(n=6)$, vasculitis $(n=1)$, joint inflammation $(n=2)$ and gasteroenteritis $(n=1)$. As these patients did not have a verified infectious disease they were not included in the statistical analysis.

\subsection{Parameters}

HGF: A commercially available ELISA kit (Quantikine HGF immunoassay, R \& D systems Inc., Minneapolis, 
Table 1. Clinical and laboratory data from patients with pneumonia.

\begin{tabular}{|c|c|c|c|c|c|}
\hline Age/Sex & ${ }^{\mathrm{a}}$ Temp1/Temp2 $\left({ }^{\circ} \mathrm{C}\right)$ & HGF1/HGF2 (ng/ml) & CRP1/CRP2 (mg/ml) & PCT1/PCT2 & Review \\
\hline $60 /$ male & $39.7 / 37.0$ & 2.19/1.13 & $169 / 118$ & $<0.1 /<0.1$ & Responder \\
\hline 52/female & $38.7 / 38.3$ & $0.55 / 0.93$ & $51 / 37.9$ & $<0.1 /<0.1$ & Non-responder \\
\hline $62 /$ female & $37.9 / 37.6$ & $0.68 / 0.75$ & $82 / 107$ & $<0.1 /<0.1$ & Non-responder \\
\hline 86/male & $36.9 / 37.0$ & $1.89 / 1.56$ & $123 / 132$ & $<0.1 /<0.1$ & Responder \\
\hline 49/male & $40.3 / 40.0$ & $0.93 / 1.19$ & $125 / 135$ & $<0.1 /<0.1$ & Non-responder \\
\hline 58/female & 39.6/38.1 & $1.52 / 1.65$ & $143 / 325$ & $51.15 / 24.97$ & Responder \\
\hline 20/male & $39.4 / 38.2$ & $2.8 / 2.8$ & $270 / 259$ & $11.78 / 0.13$ & Non-responder \\
\hline 88/female & 38.7/38.1 & $1.59 / 1.74$ & $46 / 109$ & $<0.1 / 0.19$ & Non-responder \\
\hline 93/female & $38.8 / 37.0$ & $1.37 / 1.25$ & $59 / 39$ & $0.41 / 0.15$ & Responder \\
\hline 86/male & $38.3 / 38.0$ & $6.03 / 4.7$ & $191 / 307$ & 27.02/28.99 & Responder \\
\hline 81/female & $38.0 / 37.0$ & $1.72 / 1.58$ & $31.8 / 41.6$ & $3.05 /<0.1$ & Responder \\
\hline 85/male & $39.0 / 37.1$ & $1.19 / 1.85$ & $91.2 / 219$ & $0.12 / 0.3$ & Non-responder \\
\hline 60/female & 38.1/39.1 & $6.63 / 4.36$ & $76.1 / 67.5$ & $8.84 / 4.17$ & Responder \\
\hline 85/male & $39.1 / 37.0$ & $2.65 / 1.5$ & 139/131 & $3.72 / 3.77$ & Responder \\
\hline 75/male & $39.4 / 39.4$ & 1.96/1.99 & $198 / 215$ & $0.41 / 0.73$ & Non-responder \\
\hline 43/female & $38.2 / 38.4$ & $1.3 / 1.43$ & $131 / 164$ & $<0.1 / 0.11$ & Non-responder \\
\hline 92/male & $39.0 / 38.4$ & $2.39 / 1.79$ & $115 / 152$ & $0.48 / 1.5$ & Responder \\
\hline 25/male & $40.2 / 40.0$ & $2.26 / 1.31$ & $110 / 131$ & $0.45 / 0.43$ & Responder \\
\hline 93/female & $38.2 / 37.2$ & $6.84 / 5.42$ & $249 / 202$ & $0.63 / 0.54$ & Responder \\
\hline 33/female & $39.8 / 37.8$ & $4.44 / 2.15$ & $745 / 609$ & $11.97 / 5.2$ & Responder \\
\hline 97/female & $38.6 / 37.0$ & $2.65 / 2.21$ & $97.2 / 124$ & $<0.1 / 0.23$ & Responder \\
\hline 87/male & $37.6 / 38.2$ & $4.78 / 6.82$ & $281 / 214$ & $20.28 / 26.27$ & Non-responder \\
\hline 55/male & $37.3 / 36.3$ & $3.28 / 1.58$ & $234 / 225$ & $0.94 / 0.56$ & Responder \\
\hline 85/male & $37.0 / 35.6$ & $5.31 / 2.55$ & 369/336 & $33.33 / 17.4$ & Responder \\
\hline 85/male & $37.0 / 36.8$ & $1.46 / 1.45$ & $135 / 80.3$ & $2.29 / 0.82$ & Non-responder \\
\hline 39/female & $39.4 / 37.0$ & $0.83 / 0.76$ & $52 / 37.5$ & $0.12 /<0.1$ & Responder \\
\hline 89/female & $38.0 / 37.8$ & $3.02 / 1.2$ & $111 / 176$ & $4.03 / 2.63$ & Responder \\
\hline 86/male & $37.0 / 37.8$ & $4.01 / 3.0$ & $158 / 134$ & $0.37 / 0.27$ & Responder \\
\hline 39/female & $40.0 / 40.4$ & $3.52 / 1.89$ & $280 / 423$ & $1.81 / 3.66$ & Responder \\
\hline 72/male & $39.6 / 37.1$ & $1.79 / 1.72$ & $231 / 247$ & $0.81 / 0.89$ & Responder \\
\hline
\end{tabular}

${ }^{\mathrm{a}}$ Temp 1: temperature before treatment; Temp 2: temperature within 18 hours of treatment.

Table 2. Clinical and laboratory data from patients with urinary tract infections.

\begin{tabular}{ccccccc}
\hline Age/Sex & ${ }^{a}$ Temp1/Temp2 $\left({ }^{\circ} \mathrm{C}\right)$ & HGF1/HGF2 (ng/ml) & CRP1/CRP2 $(\mathrm{mg} / \mathrm{ml})$ & PCT1/PCT2 & Diagnosis & Review \\
\hline 84/female & $38.3 / 37.9$ & $1.19 / 1.04$ & $142 / 151$ & $<0.1 /<0.1$ & UVI/Clostridie enteritis & Responder \\
39/female & $38.5 / 37.6$ & $0.68 / 0.89$ & $37 / 134$ & $0.2 / 6.15$ & Pyelonephritis/Malaria & Responder \\
74/male & $39.3 / 36.9$ & $1.52 / 1.50$ & $80 / 12.2$ & $<0.1 / 0.39$ & UVI & Responder \\
78/female & $39.0 / 37.5$ & $2.59 / 1.62$ & $209 / 230$ & $<0.1 / 0.29$ & UVI/bronchitis & Responder \\
55/male & $38.8 / 37.7$ & $3.17 / 2.62$ & $140 / 226$ & $<0.1 / 0.13$ & UVI & Responder \\
53/female & $37.0 / 37.3$ & $3.36 / 2.21$ & $494 / 459$ & $36.7 / 10.9$ & UVI & Responder \\
69/male & $38.4 / 38.1$ & $2.58 / 2.44$ & $37 / 195$ & $10.1 / 25.4$ & Pyelonephritis & Responder \\
81/male & $38.9 / 36.9$ & $1.99 / 2.6$ & $22.7 / 112$ & $53.8 / 155.4$ & Pyelonephritis & Responder \\
89/male & $39.4 / 37.8$ & $2.4 / 2.56$ & $258 / 274$ & $0.3 / 0.35$ & UVI* & Non-responder \\
79/male & $38.4 / 36.9$ & $1.52 / 1.74$ & $88 / 194$ & $0.26<0.1$ & UVI $^{*}$ & Non-responder \\
\hline
\end{tabular}

${ }^{\mathrm{a}}$ Temp 1: temperature before treatment; Temp 2: temperature within 18 hours of treatment. 
Table 3. Clinical and laboratory data from patients with skin and soft tissue infections.

\begin{tabular}{cccccc}
\hline Age & Temp1/Temp2 $\left({ }^{\circ} \mathrm{C}\right)$ & HGF1/HGF2 $(\mathrm{ng} / \mathrm{ml})$ & $\begin{array}{c}\text { CRP1/CRP2 } \\
(\mathrm{mg} / \mathrm{ml})\end{array}$ & PCT1/PCT2 & Diagnosis \\
\hline 57 & $37.4 / 37.1$ & $4.4 / 2.58$ & $266 / 189$ & $1.05 / 0.39$ & Foot ulcer infection \\
70 & $37.6 / 37.5$ & $1.39 / 4.5$ & $160 / 204$ & $0.24 / 0.94$ & Erysipelas \\
83 & $37.6 / 38.3$ & $4.57 / 3.05$ & $458 / 236$ & $7.9 / 2.58$ & Erysipelas/UVI \\
74 & $37.5 / 37.6$ & $0.78 / 0.6$ & $104 / 132$ & $<0.1 / 0.54$ & Foot ulcer, abscess \\
72 & $40.0 / 38.4$ & $1.2 / 1.4$ & $23.6 / 152$ & $0.37 / 4.91$ & Erysipelas \\
62 & $38.8 / 36.8$ & $2.29 / 2.24$ & $394 / 269$ & $2.67 / 1.63$ & Postoperative infection \\
58 & $39.8 / 38.7$ & $3.56 / 3.82$ & $205 / 261$ & $3.19 / 2.63$ & Erysipelas \\
81 & $37.6 / 36.9$ & $0.72 / 0.56$ & $8.0 / 9.9$ & $<0.1 /<0.1$ & Ulcer infection hand \\
21 & $37 / 36.8$ & $0.28 / 0.33$ & $5.8 / 4.1$ & $0.11 /<0.1$ & Erysipelas face \\
45 & $37.1 / 36.9$ & $0.46 / 0.38$ & $30.4 / 25$ & $7.11 /<0.1$ & Lymphangitis hand \\
\hline
\end{tabular}

${ }^{\mathrm{a}}$ Temp 1: temperature before treatment; Temp 2: temperature within 18 hours of treatment.

USA) was used to determine immunoreactive HGF. This method measures HGF in serum, plasma, culture media and other biological fluids. The serum samples, stored at $-70^{\circ} \mathrm{C}$, were centrifuged at $1000 \mathrm{~g}$ for 15 minutes prior to analysis. The lowest detectable amount by this assay was $0.04 \mathrm{ng} / \mathrm{ml}$.

CRP: A turbidimetric method (Hitachi 917, Boehringer Mannheim Scandinavia AB) was used for determination of CRP.

Body temperature: Measurements were taken using the First Temp Genius Thermometer (Sherwood-Davis \& Geck, USA). The First Temp Genius measures the temperature through the tympanic membrane [16].

Procalcitonin PCT: LIAISON BRAHMS PCT (Brahms Henningsdorf, Germany), a quantitative automated assay was used at Department of Biochemistry, Karolinska University Hospital, Stockholm.

\subsection{Statistics}

Baseline differences between responders and non-responders were assessed by Fisher's exact test for categorized variables and Mann-Whitney's non-parametric U-test for continuous parameters. The difference between baseline data and follow-up data with regard to the independent variables of temperature and concentrations of HGF, CRP and PCT were fairly normally distributed and, therefore, subjected to parametric tests. First, the two groups (responder and nonresponders) were tested using $t$-tests (one for each independent variable). Second, logistic regression analyses were used to judge which of the baseline/follow-up changes was the most discriminating. An ordinary discriminating analysis was also performed to assess a global cut-off value for discrimination of HGF.

\section{Results}

The clinical reports of patients were collected, and with no knowledge of test results, two extramural reviewers examined medical reports and then judged whether according to diagnosis the patient had received an appropriate type of antibiotic upon admission (responders) or not (non-responders). Responders continued with the same antibiotic regime or were switched to a similar antibiotic. Non-responders were switched to an unrelated antibiotic and/or also received surgical therapy.

\subsection{Baseline Characteristics}

There were no differences between responders and non-responders with regard to baseline data, except that patients with lung infections who were non-responders were significantly more frequent than were non-responders with either urinary tract or skin infections ( $p=0.040$, Fisher's exact test; Table 4 and Table 5).

\subsection{Discrimination between Responders and Nonresponders}

The ability of the four variables to discriminate between non-responders and responders was first tested using an ordinary $t$-test, which showed that only changes in HGF levels were significantly different between the two 
Table 4. Categorized parameters at referral.

\begin{tabular}{|c|c|c|c|c|c|c|}
\hline \multirow[t]{2}{*}{ Parameter } & & \multicolumn{2}{|c|}{ Responder $(\mathrm{n}=38)$} & \multicolumn{2}{|c|}{ Non-responder $(n=13)$} & \multirow[b]{2}{*}{$p$} \\
\hline & & $\mathrm{n}$ & $\%$ & $\mathrm{n}$ & $\%$ & \\
\hline \multirow[t]{2}{*}{ Gender } & Male & 20 & 69 & 9 & 31 & \\
\hline & Female & 18 & 82 & 4 & 18 & 0.348 \\
\hline \multirow[t]{2}{*}{ Age category } & $<73$ yr & 20 & 80 & 5 & 20 & \\
\hline & $\geq 71 \mathrm{yr}$ & 18 & 69 & 8 & 31 & 0.523 \\
\hline \multirow[t]{3}{*}{ Infection site } & Lung & 20 & 65 & 11 & 35 & $0.04 \mathrm{a}$ \\
\hline & Urinary & 8 & 80 & 2 & 20 & \\
\hline & Skin and soft tissue & 10 & 100 & 0 & 0 & \\
\hline
\end{tabular}

${ }^{a}$ Non-responders with lung infections were significantly more frequent compared with those with urinary and skin infections. Differences between responders and non-responders were assessed by Fisher's exact test.

Table 5. Continuous parameters at referral.

\begin{tabular}{|c|c|c|c|c|c|}
\hline \multirow[t]{2}{*}{ Parameter } & \multicolumn{2}{|c|}{ Responder $(\mathrm{n}=38)$} & \multicolumn{2}{|c|}{ Non-responder $(\mathrm{n}=13)$} & \multirow[b]{2}{*}{$p$} \\
\hline & Median & Q1 - Q3 & Median & Q1 - Q3 & \\
\hline Age (yr) & 71.6 & $56-84$ & 78.4 & $51-84$ & 0.757 \\
\hline Temperature $\left({ }^{\circ} \mathrm{C}\right)$ & 38.5 & $37.6-39.3$ & 38.7 & $38.2-39.4$ & 0.487 \\
\hline HGF & 2.3 & $1.4-3.5$ & 1.5 & $1.2-2.4$ & 0.099 \\
\hline CRP & 140 & $59-231$ & 131 & $89-198$ & 0.991 \\
\hline PCT & 3.9 & $0-51$ & 2.3 & $0-101$ & 0.646 \\
\hline
\end{tabular}

Differences between responders and nonresponders were assessed by a nonparametric test (Mann-Whitney U-test).

groups (Table 6). To further test the combined discriminating power of these four variables, we performed a multiple logistic regression analysis of the three non-significant variables (note that inclusion of all four variables in the model, due to high inter-correlations, caused ill-conditioned matrices that made the analysis mathematically impossible to solve). A logistic regression analysis was first made using temperature, CRP and PCT levels; an index was calculated (Temp_CRP_PCT_index $=-0.301 \times$ temp_diff $+0.000207 \times$ CRP_diff -0.0336 $\times$ PCT_diff), where diff refers to the change from referral to after treatment). Afterwards, a logistic regression was made using gender, age category, Temp_CRP_PCT_index, and HGF_diff. HGF_diff was the only significant parameter (odds ratio $=4.10 ; 95 \%$ confidence interval, $1.16-14.4 ; p=0.029$ ).

\subsection{Differences among Infection Sites}

The next question to consider was whether changes in HGF levels indicated treatment efficacy with equal success among the three infection sites. We performed a discrimination analysis to assess a global cut-off value. Examples of the sensitivity and specificity of HGF levels for this value at the three infection sites are shown in Table 7. We chose this cut-off value because it provided similarly equal sensitivity and specificity (around $80 \%$ ) for the infection sites combined, but it could, of course, be changed.

\section{Discussion}

Acute inflammatory reactions during infection can cause permanent organ damage if not properly treated. Therefore, appropriate antibiotic treatment is critical for restoring the normal physiological functions of affected organs. HGF is an indicator of organ injury [17]. It was our belief that this property of HGF could be used to predict the efficacy of treatment by monitoring the status of injury, as indicated by changes in HGF concentration. A previous study by us showed that changes in HGF concentration could function as a therapeutic marker in pneumonia [13]-[15]. In the present study, we investigated whether this might apply to other infectious diseases.

The study patients were included consequently among patients with suspect infectious diseases. The study group was therefore not aware of the ultimate diagnosis and the judgement of external reviewers. However, it was shown that the majority of included subjects with infection had pneumonia. The remaining patients suffered 
Table 6. Differences between responders and nonresponders with regard to changes in the four studied parameters, as assessed by 2-tailed $t$-test.

\begin{tabular}{|c|c|c|c|c|c|}
\hline \multirow[t]{2}{*}{ Parameter } & \multicolumn{2}{|c|}{ Responder $(\mathrm{n}=38)$} & \multicolumn{2}{|c|}{ Non-responder $(\mathrm{n}=13)$} & \multirow[b]{2}{*}{$p$} \\
\hline & Mean & SD & Mean & $\mathrm{SD}$ & \\
\hline Temperature $\left({ }^{\circ} \mathrm{C}\right)$ & -0.89 & 0.99 & -0.63 & 0.75 & 0.401 \\
\hline HGF & -0.62 & 1.04 & 0.34 & 0.54 & $0.003 \mathrm{a}$ \\
\hline CRP & 12.07 & 81.14 & 13.13 & 61.96 & 0.966 \\
\hline PCT & -1.71 & 7.26 & -0.46 & 3.78 & 0.558 \\
\hline
\end{tabular}

${ }^{\mathrm{a} O n l y}$ HGF levels were significantly different between responders and non-responders.

Table 7. Sensitivity and specificity using a global cut off value for HGF change from baseline to within 24 hours after treatment. Differences between site of infection and discriminating power of changes in HGF using an arbitrary cut off value for all infections combined.

\begin{tabular}{|c|c|c|c|c|c|}
\hline Infection site & & Responders (n = 38) & Non-responders $(\mathrm{n}=13)$ & Sens & Spec \\
\hline \multirow[t]{2}{*}{ Lung } & $\Delta \mathrm{HGF} \leq 0.042$ & 19 & 3 & & \\
\hline & $\Delta \mathrm{HGF}>0.042$ & 1 & 8 & $95 \%$ & $73 \%$ \\
\hline \multirow[t]{2}{*}{ Urinary tract } & $\Delta \mathrm{HGF} \leq 0.042$ & 6 & 0 & & \\
\hline & $\Delta \mathrm{HGF}>0.042$ & 2 & 2 & $75 \%$ & $100 \%$ \\
\hline \multirow[t]{2}{*}{ Skin } & $\Delta \mathrm{HGF} \leq 0.042$ & 6 & 0 & & \\
\hline & $\Delta \mathrm{HGF}>0.042$ & 4 & 0 & $60 \%$ & - \\
\hline \multirow[t]{2}{*}{ All diagnosis } & $\Delta \mathrm{HGF} \leq 0.042$ & 31 & 3 & & \\
\hline & $\Delta \mathrm{HGF}>0.042$ & 7 & 10 & $82 \%$ & $77 \%$ \\
\hline
\end{tabular}

from urinary tract infection or erysipelas. None of the other serious infectious diseases were diagnosed in the study material, which might depend on the fact that the more serious cases were admitted directly to other wards after inclusion, and the blood samples within 18 - 24 hours of treatment could not be collected, and therefore could not be included in the study. Thus diagnosis groups, urinary tract infection and skin and soft tissue infection, consisted of few patients. Inclusion of more patients in the individual groups counteracted the blind study design. We chose therefore to evaluate the results of this pilot study and use it to plan more oriented studies.

Circulation of an organ, pathophysiology of diseases and pharmacokinetic and bioavailability of an antibiotic are essential factors affecting treatment efficacy. During erysipelas, a deep soft-tissue infection combined with affected distal circulation is observed. In the majority of cases, several days of antibiotic therapy is required before signs of infection at the injury site begin to resolve. Early antibiotic treatment may prevent or inhibit serious complications that can result from infection. We observed that in responders with skin/soft tissue infection (erysipelas), the sensitivity of HGF to predict the efficacy of treatment was relatively low (Table 6). This might indicate serious damage to the affected organ during infection [18] as a result of impaired bioavailability of antibiotics to the swollen limb. Many patients with soft tissue infection have an ulcer from which the bacteria may have originated. The polymicrobial nature of chronic ulcers should also be taken into consideration [19]; a combination of efficient antibiotic treatment, surgery and adjuvant treatments may be required to minimize damages stemming from such infections [20] (Table 2). In patients with urinary tract infections (Table 1), there was a better correlation between changes in HGF levels measured within 18 hours of treatment and outcome (75\% sensitivity and $100 \%$ specificity). This indicates that efficient antibiotic therapy (after decompression of the bladder by catheter insertion) may be sufficient to prevent damage from occurring during urinary tract infection.

Even though these results might highlight the role of HGF as a regeneration and healing marker, it is not possible with such a small sample to draw conclusions about its role as a therapeutic marker in all infectious diseases. It is as well worth mentioning that infection caused by gram-positive bacteria in the majority of cases with erysipelas, and gram-negative bacteria in the majority of cases with urinary tract infection, makes the chosen empiric antibiotic (wide-range cephalosporin) efficient in countries such as Sweden where multiple resistant bacteria are not very common. On the contrary, in patients with pneumonia there is a variety of pathogens with different antibiotic susceptibility. Therefore the first choice of empiric treatment might not be the most efficient one. Our results from the present study show that monitoring of HGF concentrations predicted the effect of anti- 
biotic treatment in lung infections with high sensitivity. These results are in agreement with our previous observations [14] [15] and show that monitoring HGF during pneumonia might be a reasonable approach to evaluate therapy. Further studies are needed to determine if HGF has a role in the evaluation of empiric antibiotic treatment in infections caused by multiple resistant microorganisms.

In the present work HGF was compared with some old as well as quite new markers of value in judgement of treatment during infection. However, although these markers (HGF, CRP, PCT levels and temperature) increase simultaneously during infection, they are actually indicating different host responses toward infection. Determination of body temperature has been used to follow and evaluate therapy during infection for thousands of years. However, this marker is influenced by several other factors and cannot provide a reliable answer within the first day of therapy [21]. Levels of CRP rise in serum after organ injuries. However due to long half-life (8 - $21 \mathrm{~h})$ it takes more than 24 hours before levels rise or decrease at the beginning or after the effective treatment was initiated [22]. PCT (half-life, 22.3 - 28.9 h) has been widely used as a marker for sepsis in recent years [23] [24]. Still, we do not have as much experience of this protein as CRP and was therefore of importance to compare HGF results with PCT during infection. HGF is quite a stable protein [25] in serum with a biphasic clearance with an initial rapid distribution phase (t $1 / 2 \alpha=3.1$ minutes) followed by a much slower elimination phase (t $1 / 2 \beta=114$ minutes) [26]. Presumably due its relatively short half-life HGF could predict the efficacy of therapy significantly better than other markers within the first day of treatment.

The few number of cases in each group is the major limitation of this study that should completed in further studies.

\section{Conclusion}

HGF might predict the efficacy of antibiotic therapy within the first day of treatment of infection better than CRP and PCT. The results obtained in the present study together with previous observations designate the value of HGF as a first-day marker especially in pneumonia. It may be of use not only in confirming that an appropriate antibiotic is being utilized but also as an indicator of the success of treatment thus far in preventing or inhibiting damage to affected organs.

\section{Acknowledgements}

We are grateful to Dr. Aril Fryden and Dr. Sverker Sörensson for their evaluation of therapy results in the patients. We are also grateful to Barbro Furedahl for nursing assistance and to Tayeb Nayeri for laboratory assistance. This study was supported by the Research Council in Southeast Sweden (FORSS).

\section{References}

[1] Giuliano, K.K. (2001) Continuous Physiologic Monitoring and the Identification of Sepsis: What Is the Evidence Supporting Current Clinical Practice? AACN Advanced Critical Care, 17, 215-223. http://dx.doi.org/10.1097/01256961-200604000-00017

[2] Giuliano, K.K. (2007) Physiological Monitoring for Critically Ill Patients: Testing a Predictive Model for the Early Detection of Sepsis. American Journal of Critical Care, 16, 122-130.

[3] Póvoa, P. (2008) Serum Markers in Community-Acquired Pneumonia and Ventilator-Associated Pneumonia. Current Opinion in Infectious Diseases, 21, 157-162. http://dx.doi.org/10.1097/QCO.0b013e3282f47c32

[4] Póvoa, P., Coelho, L., Almeida, E., Fernandes, A., Mealha, R., Moreira, P. and Sabino, H. (2006) Early Identification of Intensive Care Unit-Acquired Infections with Daily Monitoring of C-Reactive Protein: A Prospective Observational Study. Critical Care, 10, R63. http://dx.doi.org/10.1186/cc4892

[5] Becker, K.L., Snider, R. and Nylen, E.S. (2008) Procalcitonin Assay in Systemic Inflammation, Infection, and Sepsis: Clinical Utility and Limitations. Critical Care Medicine, 36, 941-952. http://dx.doi.org/10.1097/CCM.0B013E318165BABB

[6] Schütte, K. and Malfertheiner, P. (2008) Markers for Predicting Severity and Progression of Acute Pancreatitis. Best Practice \& Research Clinical Gastroenterology, 22, 75-90. http://dx.doi.org/10.1016/j.bpg.2007.10.013

[7] Matsumoto, K. and Nakamura, T. (1991) Hepatocyte Growth Factor: Molecular Structure and Implications for a Central Role in Liver Regeneration. Journal of Gastroenterology and Hepatology, 6, 509-519. http://dx.doi.org/10.1111/j.1440-1746.1991.tb00897.x

[8] Nayeri, F., Nilsson, I., Brudin, L., Fryden, A., Söderström, C. and Forsberg, P. (2002) High Serum Hepatocyte Growth 
Factor Levels in the Acute Stage of Community-Acquired Infectious Diseases. Scandinavian Journal of Infectious Diseases, 34, 127-130. http://dx.doi.org/10.1080/00365540110077236

[9] Ohnishi, H., Mizuno, S. and Nakamura, T. (2008) Inhibition of Tubular Cell Proliferation by Neutralizing Endogenous HGF Leads to Renal Hypoxia and Bone Marrow-Derived Cell Engraftment in Acute Renal Failure. American journal of Physiology. Renal Physiology, 294, F326-F335.

[10] Mizuno, S., Matsumoto, K. and Nakamura, T. (2008) HGF as a Renotrophic and Anti-Fibrotic Regulator in Chronic Renal Disease. Frontiers in Bioscience, 13, 7072-7086. http://dx.doi.org/10.2741/3211

[11] Nayeri, F., Strömberg, T., Larsson, M., Brudin, L., Söderström, C. and Forsberg, P. (2002) Hepatocyte Growth Factor may Accelerate Healing in Chronic Leg Ulcers: A Pilot Study. Journal of Dermatological Treatment, 13, 81-86. http://dx.doi.org/10.1080/095466302317584449

[12] Nayeri, F., Nilsson, I., Skude, G., Brudin, L. and Söderström, C. (1998) Hepatocyte Growth Factor (HGF) in Patients with Pneumonia: A Comparison between Survivors and Non-Survivors. Scandinavian Journal of Infectious Diseases, 30, 405-409. http://dx.doi.org/10.1080/00365549850160729

[13] Nayeri, F., Millinger, E., Nilsson, I., Zetterström, O., Brudin, L. and Forsberg, P. (2002) Exhaled Breath Condensate and Serum Levels of Hepatocyte Growth Factor in Pneumonia. Respiratory Medicine, 96, 115-119. http://dx.doi.org/10.1053/rmed.2001.1225

[14] Nayeri, F., Brudin, L., Darelid, J., Nilsson, I., Fryden, A., Söderström, C. and Forsberg, P. (2002) Hepatocyte Growth Factor May Act as an Early Therapeutic Predictor in Pneumonia. Scandinavian Journal of Infectious Diseases, 34, 500-504. http://dx.doi.org/10.1080/00365540110080890

[15] Abednazari, H., Xu, J., Millinger, E., Brudin, L., Forsberg, P. and Nayeri, F. (2006) Hepatocyte Growth Factor Is a Better Indicator of Therapeutic Response than C-Reactive Protein within the First Day of Treatment in Pneumonia. Chemotherapy, 52, 260-263. http://dx.doi.org/10.1159/000094868

[16] Smith, D.L. and Fehling, P.C. (1996) Reliability of Infrared Tympanic Thermometry (ITT). Aviation, Space, and Environmental Medicine, 67, 272-274.

[17] Rutherford, A.E., Hynan, L.S., Borges, C.B., Forcione, D.J., Blackard, J.T., Lin, W., Gorman, A.R., Shaikh, O.S., Reuben, A., Harrison, E., Reddy, K.R., Le, W.M. and Chung, R.T. (2007) Serum Apoptosis Markers in Acute Liver Failure: A Pilot Study. Clinical Gastroenterology and Hepatology, 5, 1477-1483. http://dx.doi.org/10.1016/j.cgh.2007.08.007

[18] Celestin, R., Brown, J., Kihiczak, G. and Schwartz, R.A. (2007) Erysipelas: A Common Potentially Dangerous Infection. Acta dermatovenerologica Alpina, Panonica, et Adriatica, 16, 123-127.

[19] Dowd, S.E., Sun, Y., Secor, P.R., Rhoads, D.D., Wolcott, B.M., James, G.A. and Wolcott, R.D. (2008) Survey of Bacterial Diversity in Chronic Wounds Using Pyrosequencing, DGGE, and Full Ribosome Shotgun Sequencing. BMC Microbiology, 8, 43. http://dx.doi.org/10.1186/1471-2180-8-43

[20] Conia, P.B., Davidson, H.L. and Lipsky, B.A. (2008) The Evaluation and Treatment of Complicated Skin and Skin Structure Infections. Expert Opinion on Pharmacotherapy, 9, 717-730. http://dx.doi.org/10.1517/14656566.9.5.717

[21] Mandell, G.L., Bennett, J.E. and Dolin, R. (2009) Principles and Practice of Infectious Diseases. 15th Edition, Vol. 1, New York, Chruchill Livingstone, 604-607.

[22] Clyne, B. and Olshaker, J.S. (1999) The C-Reactive Protein. Journal of Emergency Medicine, 17, 1019-1925. http://dx.doi.org/10.1016/S0736-4679(99)00135-3

[23] Meisner, M., Schmidt, J., Hüttner, H. and Tschaikowsky, K. (2000) The Natural Elimination Rate of Procalcitonin in Patients with Normal and Impaired Renal Function. Intensive Care Medicine, 26, S212-S216. http://dx.doi.org/10.1007/s001340051146

[24] Hatzistilianou, M. (2010) Diagnostic and Prognostic Role of Procalcitonin in Infections. Scientific World Journal, 10, 1941-1946. http://dx.doi.org/10.1100/tsw.2010.181

[25] Nayeri, F., Brudin, L., Nilsson, I. and Forsberg, P. (2002) Sample Handling and Stability of Hepatocyte Growth Factor in Blood Samples. Cytokine, 19, 201-205. http://dx.doi.org/10.1006/cyto.2002.1050

[26] Liu, K., Kato, Y., Narukawa, M., Kim, D.C., Hanano, M., Higuchi, O., Nakamura, T. and Sugiyama, Y. (1992) Importance of Liver in Plasma Clearance of Hepatocyte Growth Factor in Rats. American Journal of Physiology, 263, G642-G649. 
Scientific Research Publishing (SCIRP) is one of the largest Open Access journal publishers. It is currently publishing more than 200 open access, online, peer-reviewed journals covering a wide range of academic disciplines. SCIRP serves the worldwide academic communities and contributes to the progress and application of science with its publication.

Other selected journals from SCIRP are listed as below. Submit your manuscript to us via either submit@scirp.org or Online Submission Portal.
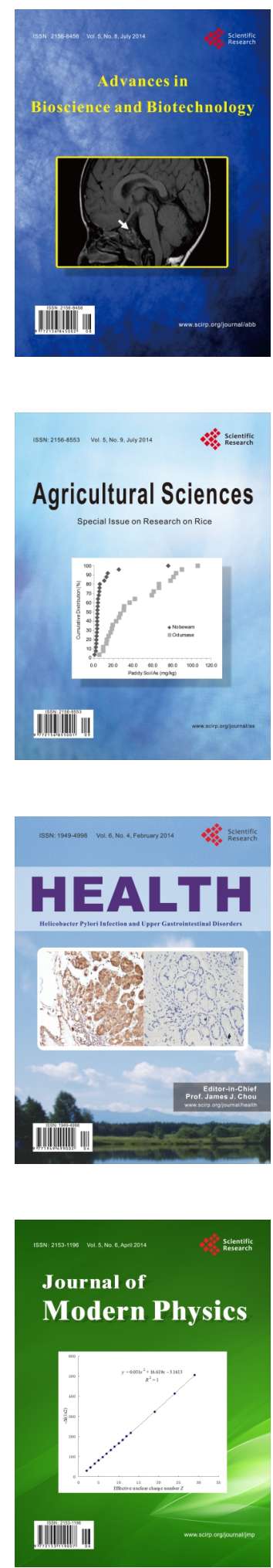
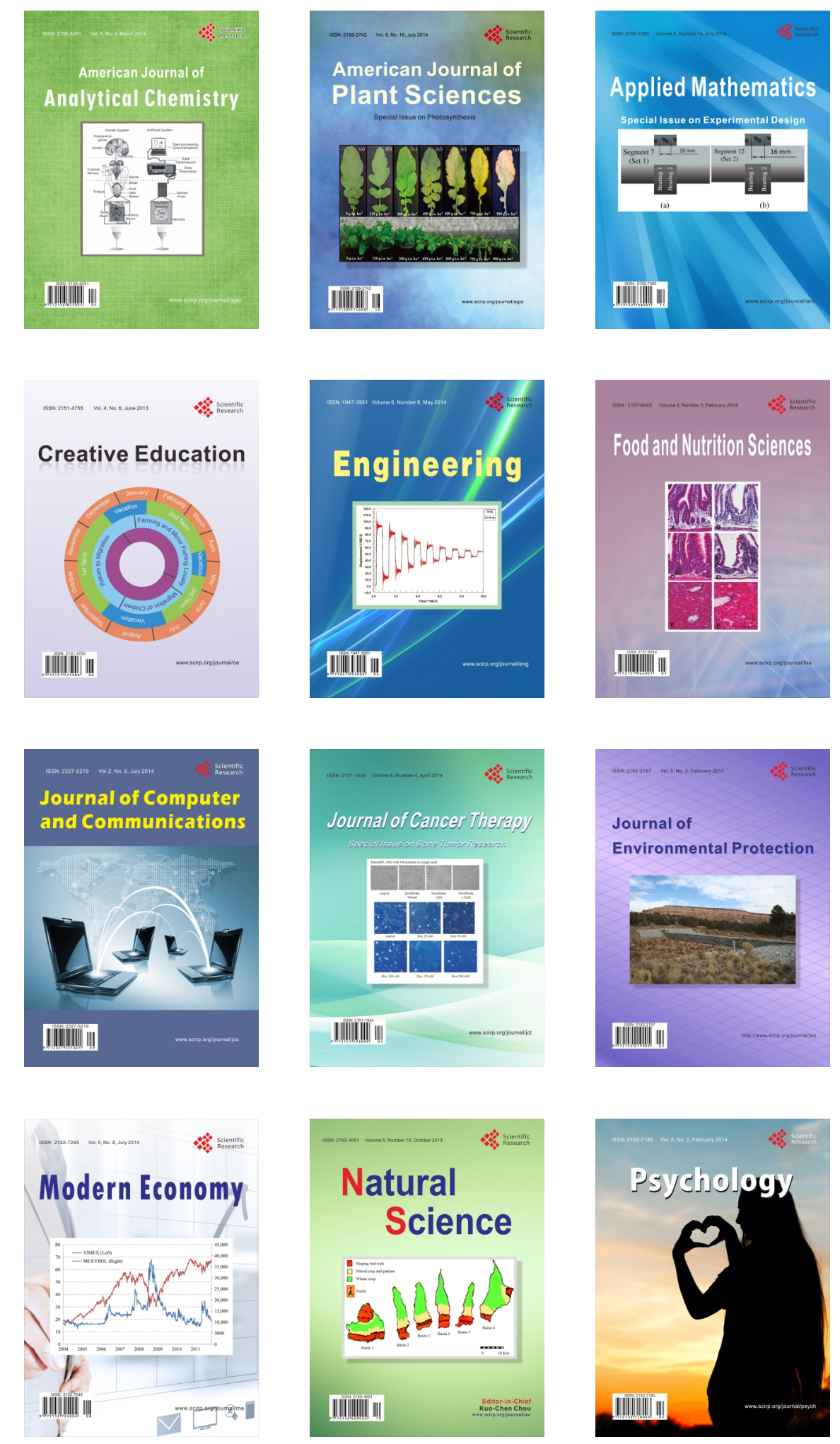